\title{
HYLOMORPHISM AND RESURRECTION
}

\author{
WILLIAM JAWORSKI
}

Fordham University

\begin{abstract}
Hylomorphism provides an attractive framework for addressing issues in philosophical anthropology. After describing a hylomorphic theory that dovetails with current work in philosophy of mind and in scientific disciplines such as biology and neuroscience, I discuss how this theory meshes with Christian eschatology, the doctrine of resurrection in particular.
\end{abstract}

\section{THE HYLOMORPHIC WORLDVIEW}

Hylomorphism claims that structure, organization, form, arrangement, order, or configuration is a basic ontological and explanatory principle. Some individuals - living things, for instance - consist of materials that are structured or organized in various ways. You and I are not mere quantities of fundamental physical materials; we are quantities of fundamental physical materials with a certain organization or structure. That structure is responsible for you and I being humans as opposed to dogs or rocks, and it is responsible for you and I having the particular developmental, metabolic, reproductive, perceptive, and cognitive capacities we have.

I'll illustrate this basic idea with three examples. The first I'll call the squashing example. Suppose we put Godehard in a strong bag - a very strong bag since we want to ensure that nothing leaks out when we squash him with several tons of force. Before the squashing the contents of the bag include one human being; after they include none. In addition, before the squashing the contents of the bag can think, feel, and act, but after the squashing they can't.

What explains these differences in the contents of the bag presquashing and post-squashing? The physical materials (whether particles or stuffs) remain the same - none of them leaked out. Intuitively we want 
to say that what changed was the way those materials were structured or organized. That organization or structure was responsible for there being a human before the squashing, and for that human having the capacities it had. Once that structure was destroyed, there no longer was a human with those capacities. Structure is thus a basic ontological principle; it concerns what things there are. And it is also a basic explanatory principle; it concerns what things can do.

A second example introduces hylomorphism by contrasting it with a more familiar view: physicalism. Physicalism claims that everything is physical; everything can be exhaustively described and explained in principle by physics. To appreciate what this means, let's imagine a character: the super physicist, a being that possesses complete physical knowledge of the universe. The super physicist has complete knowledge of all the fundamental physical entities in the universe: what they are, what properties they have, what relations they stand in, and what laws govern their behaviour. Imagine, however, that the super physicist lacks a psychological conceptual framework and even a biological one. It lacks the perceptual and conceptual tools to distinguish living things from nonliving ones or mental beings from nonmental ones. The concepts of life, perception, desire, belief, money, and so on are completely beyond its ken. As a result, when it describes the universe, its descriptions are framed solely in the vocabulary of physics - solely in terms of the characteristics of fundamental physical particles or stuffs. Because the super physicist does not have the concepts to distinguish living things from nonliving ones or mental beings from nonmental ones, its descriptions make no mention of plants, animals, or people, nor do they mention any distinctive biological or psychological activities such as growth, reproduction, perception, or belief. Nor can the super physicist recognize the distinctions these things mark in the natural world. It recognizes no difference between Godehard and the surrounding air, for instance. From its standpoint, there is just a continuous curtain of fundamental physical particles or stuffs.

Many people would be inclined to say that the super physicist's descriptions of the world would be missing some very important things: the distinction between life and nonlife or between intelligence and nonintelligence, not to mention the stock of things that tend to occupy most people's minds: money, food, sex, family, health, professional success. If physicalism is true, however, the super physicist's description misses nothing. Since everything can be exhaustively described and explained by 
physics, the super physicist's descriptions of the universe are complete as they stand. If you and I describe the universe in ways that recognize the distinctions between living things and nonliving ones or mental beings and nonmental ones, that is a comment not necessarily about what the universe contains but about how we go about describing it.

Hylomorphists disagree. In particular, they claim the super physicist misses the variety of ways physical materials are structured or organized in the natural world - ways that mark the difference between living and nonliving, mental and nonmental; that distinguish Godehard from the surrounding air, and that confer on the particles or stuffs located exactly where he is the unity that makes him a distinctive whole.

A third way of illustrating the basic hylomorphic idea of structure involves the empirical appeals to structure we find in sciences like biology and biological subdisciplines such as neuroscience. Scientists frequently appeal to notions of structure, order, or arrangement. At least some of these appeals appear to be ontologically serious; that is, they appear to posit structure as a real ontological and explanatory principle. Here is an example taken from a popular college-level biology textbook - note the references to organization, order, arrangement, and related notions:

Life is highly organized into a hierarchy of structural levels, with each level building on the levels below it ... Biological order exists at all levels ... [A] toms ... are ordered into complex biological molecules ... the molecules of life are arranged into minute structures called organelles, which are in turn the components of cells. Cells are [in turn] subunits of organisms ... The organism we recognize as an animal or plant is not a random collection of individual cells, but a multicellular cooperative ... Identifying biological organization at its many levels is fundamental to the study of life ... With each step upward in the hierarchy of biological order, novel properties emerge that were not present at the simpler levels of organization ... A molecule such as a protein has attributes not exhibited by any of its component atoms, and a cell is certainly much more than a bag of molecules. If the intricate organization of the human brain is disrupted by a head injury, that organ will cease to function properly ... And an organism is a living whole greater than the sum of its parts ... [W] cannot fully explain a higher level of order by breaking it down into its parts (Campbell 1996: 2-4).

This passage suggests that organization, order, structure, or arrangement is a real feature of things, one that plays an important role in them being 
the kinds of things they are, and in explaining the kinds of things they can do. It suggests, in other words, that structure is a real ontological and explanatory principle.

This idea is echoed by other scientists and by some philosophers. ${ }^{1}$ The biologist Ernst Mayr is an example:

All biologists ... recognize no supernatural or immaterial forces, but only such that are physico-chemical ... [T] he modern biologist rejects in any form whatsoever the notion that a 'vital force' exists in living organisms which does not obey the laws of physics ... All processes in organisms ... strictly obey these physical laws ... But [biologists] do not accept the naïve mechanistic explanation of the seventeenth century and disagree with the statement that animals are 'nothing but' machines ... Where organisms differ from inanimate matter is in the organization of their systems ... [O] rganisms have many characteristics that are without parallel in the world of inanimate objects. The explanatory equipment of the physical sciences is insufficient to explain complex living systems (Mayr 1982: 2, 52).

Empirical appeals to structure of the foregoing sort provide a way of understanding what hylomorphism claims.

Many philosophers find empirical appeals to structure like these obvious and unremarkable: How could anyone question (and hence why would anyone bother to mention) that structure factors into things? But the notion of structure does not come for free - at least not if we endorse what I'll call 'ontological naturalism', a position that conjoins a Quinean view of ontological commitment with a broad empiricism: We are committed to all the entities postulated by our best descriptions and explanations of reality, and those descriptions and explanations derive from empirical sources, paradigmatically the natural and social sciences. If we accept ontological naturalism, appeals to structure like the foregoing make a serious ontological demand. We can try to satisfy it in at least four different ways.

Three of these ways claim, contrary to what the foregoing quotes suggest, that everything can be exhaustively described and explained without appealing to structure, that appeals to structure can either be eliminated, reduced, or paraphrased so that we need not in principle

${ }^{1}$ Examples include J.B.S. Haldane (1947: 54-56), Gerd Sommerhoff (1969: 147-148), J.Z. Young (1971: 86-87), Jonathan Miller (1982: 140-141), Michael Ruse (2001: 79), John Locke (1959: Book II, Chapter 27, Sections 5-9), and John Dewey (1958: 253-8). 
speak as if structure really exists. Daniel Dennett (1991) has a view of this sort; he claims that we postulate patterns or structures purely as a matter of explanatory or predictive convenience. ${ }^{2}$

Unlike views of this sort, hylomorphism takes claims about structure in the sciences at face value. It takes structure to be a real, irreducible ontological and explanatory factor - a view I'll call structure realism. ${ }^{3}$

Structure realism by itself is compatible with physicalism. It could turn out that there are structures, but that the only structures that exist are those postulated by physics. Structure realism is also compatible with views like substance dualism. ${ }^{4}$ Yet neither of these is the kind of view expressed in the foregoing passages from biologists. That view is committed to the claim that we are organisms, contrary to substance dualism. And it is committed to the claim that there are basic structures other than those postulated by physics, contrary to physicalism. It distinguishes what physics by itself can describe and explain from what appeals to biological, or psychological, or social structure enable us to describe and explain. Because of this, its exponents often claim that organisms are not mere machines, as Mayr puts it, but have characteristics - emergent properties, to use Campbell's term - not found among nonliving things, and so they conclude that the explanatory apparatus of physics is insufficient to describe and explain living behaviour; it gets at 'only half the truth', as the cyberneticist Gerd Sommerhoff (1969) puts it. What it misses are the things that can only be described and explained

2 This is also a view Mark Johnston describes (and rejects): 'When certain items come to stand in certain relations ... there then comes to be some further item which has those original items as parts. That is ... how we have such complex items as model airplanes, trains, and molecules ... [J] ust why are those relations ... "item-generators", while other relations ... seem impotent in the production of new items?... Could it just be a projection of our idiosyncratic way of experiencing and conceptualizing reality, so that things considered in themselves are not complex, but are so only relative to a scheme of clumping or bundling? Somehow, I doubt it' (Johnston 2006: 652).

${ }^{3}$ This should not be confused with the view Ladyman and Ross (2007) call 'structural realism. Their view rejects commonsense things, and takes a stance on the empirical contents of physics. Structure realism does neither.

${ }^{4}$ Substance dualism claims that persons, such as you and I, are distinct from human organisms; we are nonphysical entities. Suppose that substance dualism is true, and further, that human organisms consist of physical materials that are structured a certain way. The upshot is a substance dualistic view that is committed to hylomorphism. Structure is a basic principle that factors into descriptions of what human organisms are and what they can do; it simply doesn't factor into descriptions of what we, nonphysical persons, are and what we can do. 
by appeal to structure at a biological, psychological, or social level. I'll reserve the term 'hylomorphism' for a structure realist view of this sort.

Since the label 'hylomorphism' is not new it's worth mentioning that the view I have in mind differs from those of Kit Fine (1999), Mark Johnston (2006), David Oderberg (2007), and Kathryn Koslicki (2008). Moreover, I cannot vouch for its similarities to the views of Aristotle, Aquinas, Leibniz, Merleau-Ponty, or any of the other philosophers whose views have been labelled 'hylomorphic. ${ }^{5}$ It is nevertheless very similar to the view Montgomery Furth (1978) attributes to Aristotle. ${ }^{6}$

The foregoing passages from biologists suggest a hylomorphic view with at least five characteristics. First, hylomorphism takes the distinction between living things and nonliving ones (and also, as we'll see, between mental beings and nonmental ones) to be grounded in their organization or structure. ${ }^{7}$ These distinctions are due not to the entities that compose them, but to the way those entities are structured or organized.

Second, living things such as human beings are exhaustively decomposable into particles or materials of the sort described by physics, the very same particles or materials found in nonliving things. Someone

${ }^{5}$ For Aristotle's view see Physics, Book II, Chapters 1-3, and On the Soul, as well as Nussbaum and Putnam (1992). For Aquinas' view see Summa Theologiae Ia, Questions 75-86, and Leftow (2001); for more on Leibniz see Garber (1985) and Smith (2002), and see Merleau-Ponty (2002) for his view.

6 '[The world] is an Empedoclean, finite three-dimensional mass, entirely filled with the four elements ... [W]e now observe that scattered through this three-dimensional mass there are innumerable knots, regions where the matter is elaborately and intricately worked up into an organic unity ... highly convoluted but relatively stable eddies in the general commingling-and-separation [of elements] ... Aristotle thinks the "principle" called "form" must be brought in on top of the Empedoclean basis, to explain the stability of the knots and the complex specific character that they manifest as long as they last ... a material individual (i.e., animal) is ... a semipermanent warp or bend informing the local matter, which the matter flows through at various rates during the organism's life history ... while the form imposes the continuity ... (Furth 1978: 638-9). One difference between the view I have in mind and Aristotle's is that the view I have in mind is not committed to a specific account of fundamental physical entities. It does not claim that they are Empedoclean stuffs, as Aristotle's account does, but is happy to leave it to physicists to determine what they are.

7 Hylomorphism is thus at odds with views that ground these distinctions in the particles or materials that compose things. Democritus, for instance, claimed that the differences between living things and nonliving ones could be explained by a greater proportion of spherical atoms. More recently, Roger Penrose has suggested that the difference between conscious beings and nonconscious ones can be explained by differences among their quantum-level components. 
could endorse a hylomorphic view according to which living or mental beings have nonphysical components. Aquinas, for instance, may have endorsed a view of this sort. The hylomorphic view I have in mind, however, rejects this idea. It is committed instead to the empirical claim expressed in the quote from Mayr: living, mental beings such as humans have only physical components; they are exhaustively decomposable into the same fundamental physical materials found in nonliving things.

Third, because organisms consist of both structures and materials that are structured, hylomorphists claim that a complete account of living behaviour must appeal to both. This claim has at least two important implications. First, it implies a pluralism of properties.

On the hylomorphic view, living things have properties of at least two sorts: properties that are due to their structures (or their integration into individuals with structures), and properties that are due to their materials alone independent of the way those materials are structured. Consider an example. Subatomic particles, atoms, and molecules have physical properties such as mass irrespective of their surroundings. Under the right conditions, however, they can contribute to the activities of living things. Nucleic acids, hormones, and neural transmitters are examples; they are genes, growth factors, and metabolic and behavioural regulators. Each admits of two types of descriptions which express two types of properties. They can be described organically, in terms of the contributions they make to a structured system, but they are also independently describable in nonorganic, non-contribution-oriented terms. Descriptions of the former, organic sort express the properties characteristic of organisms and their parts. Descriptions of the latter, nonorganic sort express the properties things possess independent of their integration into organic wholes. A strand of DNA might always have various atomic or fundamental physical properties regardless of its environment, but it acquires new properties when it is integrated into a cell and begins making contributions to the cell's activities. It becomes a gene, a part of the cell that plays a role in, for instance, protein synthesis.

Some people call these new properties 'emergent properties' (Campbell in the earlier quote is an example). Emergent properties have several characteristics (Jaworski 2011). I won't describe them in detail here; I'll simply note in passing that included here there is no condition that requires emergent properties to be produced or generated by lowerlevel things. That is because hylomorphists, unlike classic emergentists, deny that this is the case. Structure, they say, is basic. It is not generated 
by anything. We can, as an empirical matter of fact, they say, describe how particular structures came to be in place: my distinctively human structure came initially to inform various biotic materials because of my parents' reproductive activity. What hylomorphists deny is that it would be legitimate to ask what it currently is that is responsible for continually generating the structure I have. Structures are not generated by the things they structure.

There are, then, properties that depend on something's structure and properties that things possess independent of a broader structure. According to hylomorphists, properties of both sorts make causal or explanatory contributions to the things having them. These contributions reflect a second implication of the idea that a complete account of living behaviour must appeal to both structure and materials that are structured, namely, causal pluralism: there are different kinds of causal or explanatory factors, and different kinds of causal or explanatory relations.

A car crash, for instance, involves the convergence of numerous factors - faulty brakes, insufficient roadway grading, inadequate signage, and alcohol. The ways these factors contribute to the crash vary. We can understand how the brakes and the roadway contribute purely by appeal to physics. Understanding how the alcohol contributes, by contrast - its effects on, say, perception and reaction time - requires the conceptual resources of biology, and understanding how the inadequate signage contributes requires the conceptual resources of psychology - resources for understanding how animals like us can use symbolic systems and modulate their behaviour in light of the information those systems convey.

One way of giving content to the idea that there are different kinds of causes and causal relations is to view causal relations as explanatory ones, and to view explanations as answers to certain kinds of questions. Aristotle defended an account of causation and explanation along these lines. A cause (aitia), he said, was an answer to the question dia ti: 'Why?' or 'On account of what?' (Physics 194b16-20). Bas van Fraassen has made a similar claim: 'An explanation', he says, 'is an answer to a why-question' (1980: 134). Elsewhere I've developed this idea not just with regard to why-questions but also how-questions since many how-questions are requests for explanation as well (Jaworski 2009). Examining the logic of why- and how-questions can thus provide a starting point for cataloguing the range of explanatory factors and relations we seek to understand when we ask 'Why?' or 'How?'. 
A quick illustration: van Fraassen has shown that explanation is contrastive. When we ask why something happened - e.g. 'Why did Adam eat the apple?' - it remains unclear exactly what we are saying: Do we mean 'Why did Adam eat the apple (in contrast to the papaya, or the mango, or ...)?'. Or do we mean 'Why did Adam eat the apple (in contrast to having thrown it away, or having done something else with it)?' Or do we mean why did Adam eat the apple (in contrast to the serpent or someone else)? A similar point comes out with how-questions.

'How did Judith kill Holofernes?'

Answer A: 'With a mixture of revulsion and determination.'

Answer B: 'With a mixture of bile and snake venom.'

Answer C: 'With a mixture of seduction and cunning.'

The first answer supplies the manner; the second supplies the method, and the third supplies the means. Manners, methods, and means are among the things we ask about with how-questions. We also ask about mechanisms.

How-questions of mechanism request what some philosophers of neuroscience call mechanistic explanations (Bechtel 2007). They explain how a system is able to perform an activity by describing how the activities of its subsystems contribute to it. (I'll return to this idea momentarily when I discuss functional analysis, the method whereby empirical researchers discover mechanisms.)

So on this view causes and causal relations are explanatory. By examining the range of ways we explain things in our pedestrian dealings and in our scientific practices we can start compiling an inventory of the kinds of causes and causal relations there are.

A fourth feature of the hylomorphic view is this: Because living things are composed of fundamental physical entities, their behaviour never violates fundamental physical laws, the laws governing their fundamental physical constituents.

Fifth, hylomorphism's view of structure is closely related to an account of composition or parthood. According to hylomorphists, lower-level entities such as atoms and electrons qualify as parts of higher-level entities such as organisms by virtue of contributing to their activities. An electron is a part of me, for instance, exactly if it contributes to my overall functioning - if, say, it contributes to depolarizing one of my cellular membranes or plays a role in the metabolic processes of one of my cells. Consider again the strand of DNA. When it is integrated into a cell, it makes a goal-directed contribution to the activity of the whole. 
As a result, it gains the status of an organic part. It and parts like it are literally organ-ized in living things: they become organs.

On the hylomorphic view of composition, then, parts contribute to the activities of the wholes they compose, and different parts of a whole contribute to its activities in different ways.

Peter van Inwagen has recently defended a similar account of composition. According to van Inwagen, something qualifies as a part if and only if it is 'caught up in a life', an expression he borrows from the biologist J.Z. Young. He explains with an example:

Alice drinks a cup of tea in which a lump of sugar has been dissolved. A certain carbon atom ... is carried along ... by Alice's digestive system to the intestine. It passes through the intestinal wall and into the bloodstream, whence it is carried to the biceps muscle of Alice's left arm. There it is oxidized in several indirect stages (yielding ... energy ... for muscular contraction) and is finally carried by Alice's circulatory system to her lungs and ... breathed out as a part of a carbon dioxide molecule ... Here we have a case in which a thing, the carbon atom, was ... caught up in the life of an organism, Alice. It is ... a case in which a thing became however briefly, a part of a larger thing when it was a part of nothing before or after ... (Van Inwagen: 94-5)

Hylomorphism's account of composition can be understood as a way of elaborating van Inwagen's basic idea: to be caught up in the life of something is to make a goal-directed contribution to its activities, where it is up to biologists, neuroscientists, and other empirical investigators to describe the nature of this goal-directed contribution.

An account of composition like this has also been endorsed by several philosophers of biology including William Bechtel, a philosopher of neuroscience. According to Bechtel, something qualifies as a component part of a complex system - what he calls a mechanism - only if it performs an operation that contributes to the activity of the whole. ${ }^{8}$

8 The hylomorphic view of parts and wholes assumes a specific kind of metamereology. Kathrin Koslicki describes it this way: 'I take the mereologist's job to be to devise an appropriate conception of parthood and composition which accurately reflects the conditions of existence, spatio-temporal location and part/whole structure of those objects to which we take ourselves to be already committed as part of the presupposed scientifically informed, commonsense ontology. The question of which kinds [of objects] there are I take to be ... answered [not] by the mereologist proper, but by the ontologist at large, in conjunction with ... science and common sense, which ... have something to contribute to the question, "What is there?" ... [M] ereology ... does not settle matters of 
Philosophers of biology and neuroscience, like Bechtel, have been attracted to a view of composition along these lines because this is the type of view suggested by actual work in biology and neuroscience both the methods of those sciences and the kinds of explanations they employ. Of central importance is a method of scientific investigation philosophers have sometimes called 'functional analysis' (other names include 'mechanical decomposition' or 'functional decomposition'). Biologists, cognitive scientists, engineers, and others frequently employ this method to understand how complex systems operate. They analyze the activities of those systems into simpler subactivities performed by simpler subsystems. ${ }^{9}$

Consider a complex human activity such as running. Functional analysis reveals that running involves among other things a circulatory subsystem that is responsible for supplying oxygenated blood to the muscles. Analysis of that subsystem reveals that it has a component responsible for pumping the blood - a heart. Analysis of the heart's pumping activity shows that it is composed of muscle tissues that undergo frequent contraction and relaxation, and these activities can be analyzed into the subactivities of various cells. Analyses of these subactivities reveal the operation of various organelles that compose the cell and that are composed in turn of complex molecules. We can continue to iterate the process until we reach a level at which no further functional analysis is possible. If, for instance, electrons contribute to the activities of things by virtue of having negative charges, and they have those charges not on account of the activities of some yet lower-level subsystems, but as an unanalyzable matter of fact, then no further functional analysis is possible. We reach a foundational level of functional parts.

ontological commitment; rather, it presupposes them to be resolved elsewhere within metaphysics or outside of philosophy altogether ... [This] approach differs from the standard conception as well as from Fine's theory of embodiments ... which view the mereologist as a specialized sort of ontologist, whose job ... is precisely to tell us what mereologically complex objects (if any) the world contains ... [B]y presupposing that the question, "What mereologically complex objects (if any) are there?" is descriptively settled in the course of arriving at a scientifically and commonsensically acceptable ontology of kinds, the present approach assigns to the mereologist proper a more limited set of responsibilities ... characteriz[ing] ... those mereologically complex entities whose existence is already confirmed by independent evidence' (2008: 171).

9 See, for instance, Fodor (1968), Cummins (1975), Dennett (1978), Lycan (1987 Chapter 4), Bechtel (2007), and Craver (2007: Chapter 5). 
Functional analysis provides a way of supplying empirical content to the idea that parts contribute to the activities of their respective wholes. If we want to know how a part contributes to the activity of a whole, hylomorphism leaves it to the relevant empirical disciplines to tell us.

Two clarifications are in order about functional analysis. First, a remark about the name: 'Functional analysis' is a name that has been used by philosophers, but biologists often call the method 'reduction'. This notion of reduction is different from the notion typically discussed in connection with the philosophy of mind (Jaworski 2011). Reduction in the philosophy of mind typically concerns the ability of one conceptual framework to take over the descriptive and explanatory roles of another. To claim that, say, psychology is reducible to neuroscience implies that it is possible in principle for neuroscience to take over all the descriptive and explanatory roles psychology currently plays. Any description or explanation we would normally express in psychological terms could be rewritten in principle solely in neuroscientific terms. If this kind of rewriting were possible, then neuroscience would be capable of taking over all the descriptive and explanatory roles psychology plays. Psychology would be reducible to neuroscience.

By contrast, when biologists speak of reduction they are typically not speaking of the relation between conceptual frameworks I've just described, but of a method for studying complex systems - what I've been calling 'functional analysis'. Here is an example taken from the biology textbook quoted earlier:

Reductionism - reducing complex systems to simpler components that are more manageable to study - is a powerful strategy in biology ... Biology balances the reductionist strategy with the longer-range objective of understanding how the parts of cells, organisms, and higher levels of order, such as ecosystems, are functionally integrated (Campbell, et al. 1999: 4).

The authors clearly have in mind what they call a research strategy - a method for studying complex things. A commitment to employing this method does not imply a commitment to reduction in the philosophical sense. It might be impossible for neuroscience to take over the descriptive and explanatory roles of psychological discourse even though it is possible and even necessary to use functional analysis to understand how humans can engage in psychological activities. ${ }^{11}$ In fact, this is precisely what hylomorphists claim. Explanations of living behaviour are not 
reducible to descriptions of the lower-level mechanisms revealed by functional analysis because of the distinctive explanatory contributions a living thing's biological, psychological, and social structures make.

Why should we believe that hylomorphists are right about higher-level structures making explanatory contributions beyond the contributions made by their lower-level parts? Hylomorphists insist that this is supported by empirical considerations. As an empirical matter of fact, they say, higher-level structural discourse provides effective descriptions and explanations independent of any claims about reducibility. Consider Bechtel's observations about descriptions and explanations in psychology and other special sciences:

[The] mechanistic explanations [provided by functional analysis] are in fact compatible with a robust sense of autonomy for psychology and other special sciences ... In virtue of being organized systems, mechanisms do things beyond what their components do ... Organization itself is not something inherent in the parts. Accordingly, investigators who already understand in detail how the parts behave are often surprised by what happens when they are organized in particular ways ... [T] he organization of the components typically integrates them into an entity that has an identity of its own. As a result, organized mechanisms become the focus of relatively autonomous disciplines ... This autonomy maintains that psychology and other special sciences study phenomena that are outside the scope of more basic sciences but which determine the conditions under which lower-level components interact. In contrast, the lowerlevel inquiries focus on how the components of mechanisms operate when in those conditions ... The fact that mechanisms perform different activities than do their parts manifests itself in the fact that the activities of whole mechanisms are typically described in [a] different vocabulary than are component operations. Traditional accounts of theory reduction implicitly recognized this fact by requiring bridge principles to connect the different vocabularies used in different sciences, but little notice was given as to why different sciences employ different vocabularies. The vocabulary used in each science describes different types of entities and different operations - one describes the parts and what they do, whereas another describes the whole system and what it does (2007: 174, 185-186).

10 John Bickle (2003) refers to the philosophical sense of reduction as 'ruthless reduction'; Bechtel (2007: 173-4) and others have distinguished this from reduction in the methodological sense - what we are calling 'functional analysis'. 
If Bechtel's observations of scientific practice are correct, higher-level empirical disciplines and lower-level ones have different subject-matters on account of the ways things are organized or structured. Because higherand lower-level disciplines deal with different subject-matters, they have different vocabularies, and provide different kinds of explanations, and these different vocabularies and explanations make higher-level disciplines autonomous - irreducible to lower-level disciplines in the traditional philosophical sense. In light of these kinds of observations about the autonomy of higher-level sciences, and the role structure or organization plays in explaining it, hylomorphists insist that the burden of proof is on their opponents to establish that claims about biological, psychological, or social structures are reducible to claims about things that lack them.

A second note about functional analysis: the notion of function that gives functional analysis its name is different from the notion of function discussed in connection with functionalism in philosophy of mind. According to classic functionalist theories of mind, mental states are postulates of abstract descriptions framed in terms analogous to those used in computer science - descriptions that ignore the physical details of a system, and focus simply on a narrow profile of its features: inputs to it, outputs from it, and internal states that correlate the two. ${ }^{11}$

When it comes to functional analysis, by contrast, the notion of a function is not abstract in this way, and it has a teleological dimension: subsystems contribute to the activities of the wholes to which they belong, and that contribution is their reason or 'purpose' for belonging to the system: the purpose of the spark plug is to ignite the fuel; the purpose of the heart is to pump the blood, and so on.

Teleological functionalism is a type of functionalist theory that appeals to a teleological notion of function along these lines as well. Lycan's

\footnotetext{
${ }^{11}$ See Hilary Putnam's 'The Mental Life of Some Machines, 'The Nature of Mental States', and 'Robots: Machines or Artificially Created Life?', in Putnam (1975). According to Putnam's original proposal, psychological descriptions are abstract descriptions that postulate relations among sensory inputs, motor outputs, and internal mental states. The only significant difference between Turing machine descriptions and psychological descriptions, Putnam suggested, was that psychological inputs, outputs, and internal states were related to each other probabilistically not deterministically. If, for instance, Eleanor believes there are exactly eight planets in our solar system, and she receives the auditory input, 'Do you believe there are exactly eight planets in our solar system?', then she will produce the verbal output, 'Yes', not with a deterministic probability of 1 , but with a probability between 1 and 0 .
} 
(1987: Chapter 4) homunctionalism is an example. ${ }^{12}$ Like functionalist theories of all sorts, however, teleological functionalism claims that higher-level discourse is abstract discourse; higher-level properties are higher-order properties - logical constructions that quantify over lowerorder properties. Saying that something has a belief, for instance, amounts merely to saying that it has some internal state that correlates inputs with outputs in appropriate ways. Hylomorphists reject this understanding of higher-level properties. They claim that higher-level properties are first-order properties in their own right. So although teleological functionalists and hylomorphists both claim that a system's components contribute teleologically to its overall operation, they disagree about how the notion of contribution is to be understood. Teleological functionalists say that descriptions of higher-level phenomena are simply abstract descriptions of lower-level occurrences. Hylomorphists deny this. Higher-level descriptions correspond to distinctive natural structures, ones that factor into descriptions and explanations of living behaviour in ways that cannot be eliminated, reduced to, or paraphrased in favour of lower-level descriptions and explanations.

Let this suffice for a description of the general hylomorphic view. I've discussed an argument for it in detail elsewhere (Jaworski 2011: Chapter 10; cf. Ellis 2002: 173). Rather than rehearsing it here, I want to consider a hylomorphic approach to mental capacities - what I will call a hylomorphic theory of mind. It takes the biological notion of structure we've been focusing on and extends it into the psychological domain.

\section{PATTERNS OF BEHAVIOUR: A HYLOMORPHIC THEORY OF MIND}

The grail of philosophy of mind for over 40 years has been an acceptable mind-body theory that is both antireductive and broadly naturalistic - a theory that affirms that we are physical beings with physical components, but that also denies that biology, psychology, and other special sciences are reducible to physics. Theories of this sort include various forms of nonreductive physicalism and emergentism. Hylomorphism is a theory of this sort, but it rejects both physicalism and some of the central tenets of emergentism. I'll briefly describe the basic idea behind a hylomorphic theory of mind before turning to the question of whether hylomorphism is compatible with the doctrine of resurrection.

${ }^{12}$ See also Sober (1985: Section 3). 
When people think of structures they often think of what we might call mechanical structures or mechanisms: spatial arrangements among a thing's parts that enable those parts to interact in novel ways - ways that confer on the whole capacities not had by the parts taken in isolation. Hylomorphists acknowledge the existence of mechanisms, but they insist that mechanical structures are not the only kinds of structures that exist. Biological organization also comprises patterns of behaviour - the characteristic ways that living things interact with each other and their environments.

Living things do not act at random. Birds build nests not webs, and lay eggs not acorns. Humans grow lungs instead of gills, and skin instead of scales. Squirrels bury nuts, and are active during the day; raccoons come out at night, and rummage through our garbage. All of these are examples of patterns in living behaviour. Just as the parts of living things are not assembled at random but have distinctive structures, so too the behaviour of living things is characterized by distinctive patterns of social and environmental interaction.

Some of these patterns involve the ways organisms acquire and utilize energy from the environment to maintain their distinctive structures against entropy. Others involve their abilities to respond to and interact with features of their environments - their capacities for sensation and movement, for instance. Yet other patterns involve states of motivation or arousal such as hunger, thirst, fear, anger, and enjoyment; and still others involve cognitive capacities such as memory, learning, reasoning, and problem solving.

According to hylomorphists, the patterns we find in the living world include mental phenomena. Thought, feeling, perception, and action are all patterns of social and environmental interaction. Some we describe in perceptual or sensory terms: seeing, hearing, tasting, feeling. Others are more complex and incorporate perceptual or sensory patterns of these sorts. They include believing, wanting, knowing, and remembering. These higher-level patterns, moreover, are often integrated into behavioural patterns that are more complex still such as intellectual habits or personality or character traits. Consider an example: The interactions between a young child and the candy hidden in the cupboard are at first almost completely unstructured - or more precisely, they are structured in ways we can describe and explain merely by appeal to physics: the child and the candy exert a gravitational influence on each other, for instance. But the interactions between the child and the candy become 
structured in more complex ways once the cupboard door is opened. We describe these ways using a psychological vocabulary: we say the child wants the candy, is trying to get it, and remembers that it is there once its mother has re-closed the cupboard door. The same is true of the child's interactions with its mother and with other people: it is chagrined and frustrated by her refusal to give the candy, but knows that its father is more pliable. Similarly, the father's pliability and the mother's prudence are also types of complex structured behaviour. They represent broad patterns of choice, decision, thought, feeling, and action with long histories and long-term implications for future behaviour.

The core idea of a hylomorphic theory of mind, then, is that sensations, feelings, thoughts, perceptions, actions, and other psychological phenomena are complex patterns of social and environmental interaction like the patterns just described. They are ways animals like us interact with each other and the environment - ways in which our behaviour is structured or organized. Living things are not just organized assemblages of parts; they are zones of structured activities. These activities include muscular contractions, bodily movements, and other physiological states as lower-level contributing factors, but they also include higherlevel interactions with other living things and the environment. Human behaviour in particular comprises biological activities and capacities that are incorporated into patterns of rational interaction, patterns that admit of evaluation in terms of rational, moral, aesthetic, and similar categories. What get structured in these rational ways include the states and subactivities of various organic parts, such as the parts that enable humans to perceive aspects of their social and physical environments and to feel and respond to those features. These forms of engagement and response, and the criteria we use to evaluate them are in part what we refer to and describe when using psychological predicates and terms. On the hylomorphic view, then, we use psychological discourse to describe high-level structured behaviours that have various organic states as lower-level contributing substructures. ${ }^{13}$

13 The idea that mental phenomena are patterns of social and environmental interaction is liable to remind some readers of behaviourism, and others of Dennett's (1992) real patterns. Elsewhere I've described in detail how hylomorphism differs from these views (Jaworski 2011; Jaworski 2012). Briefly, hylomorphism (of the sort we are considering) rejects physicalism, whereas behaviourism and Dennett do not. In addition, hylomorphists do not conceive of behaviour as narrowly as behaviourists do. According to hylomorphists, behaviour comprises not mere bodily movements 


\section{THE COMPATIBILITY OF HYLOMORPHISM AND THE RESURRECTION}

Elsewhere I've shown in detail how a hylomorphic framework like the one I've just described is able to solve mind-body problems such as the problem of mental causation, the problem of emergence, and the problem of other minds (Jaworski 2011; Jaworski 2012). My goal here, however, is to explain why such a view is compatible with the doctrine of resurrection. I will call this the 'compatibility thesis. To frame discussion of the compatibility thesis I will consider an argument against it:

(1) If hylomorphism is true, then I will be raised from the dead only if (a) God can bring it about that some materials have a distinctively human structure, and (b) God can ensure that those structured materials compose me and not someone else. [Premise]

(2) God cannot satisfy conditions (a) and (b) at a time after I die. [Premise] Therefore, if hylomorphism is true, I will not be raised from the dead.

The inference is valid, so if the premises are true, the compatibility thesis is false. Support for Premise 1 derives from a plausible line of reasoning. If hylomorphism is true, then I am essentially materials with a distinctively human structure. I am, moreover, essentially myself and not someone else. From these claims it follows that at any time at which I exist there must be materials that have a distinctively human structure and that compose me and not someone else at that time. Suppose now that I have been raised from the dead at time t. In that case I must exist at $t$, for I take it that the idea of resurrection entails that the individual who is raised from dead is I myself and no one else. If hylomorphism is true, this implies that at $t$ there must be materials that have a distinctively human structure and that compose me and no one else. Consequently,

and gestures, as behaviourists suppose; it comprises social and environmental factors as well. Third, hylomorphists and behaviourists endorse different semantics for psychological expressions. According to behaviourists, psychological expressions operate like abbreviations for longer physical descriptions of bodily movements and states. According to hylomorphists, by contrast, psychological expressions operate like natural kind terms that refer to patterns of social and environmental interaction, and that get their referents fixed initially by observing those patterns firsthand (Jaworski 2011: 334-339). Hylomorphists thus reject the behaviourist project of analyzing psychological predicates and terms into longer descriptions of actual and potential bodily movements and states. Finally, hylomorphism is committed to structure realism whereas Dennett's view is a variety of structure antirealism. According to him, we postulate patterns simply for predictive and explanatory convenience. For more on the varieties of structure antirealism see Jaworski (2012). 
if God is to bring it about that I am raised from the dead at $t$, God must bring it about that some materials have a distinctively human structure at $t$ and compose me and no one else. It is not enough that God should create a mere duplicate of me. It must be the case that by structuring materials humanwise at $\mathrm{t}$, God brings it about that I am the individual those materials compose.

Premise 2 is supported by another plausible line of reasoning. According to hylomorphists, dying is ceasing to exist. When an organism dies, the materials that compose it lose their distinctively biological structure. But that structure is essential to the organism; the organism cannot exist without it. So on the hylomorphic view organisms cease to exist when they die. But I am a human organism on the hylomorphic view; I am essentially materials with a distinctively human structure. Consequently, if I lose that distinctively human structure, then I will cease to exist, and this is precisely what will happen when I die. Now, say critics of the compatibility thesis, if something ceases to exist at a time, then it is metaphysically impossible for it to exist again at a later time. Let us call this premise the 're-existence restriction'. From the re-existence restriction it follows that if hylomorphism is true, I cannot exist at a time after I die. But if I cannot exist at a time after I die, then God cannot satisfy conditions (a) and (b) at a time after I die, for it is not within the scope even of God's omnipotence to bring about a metaphysical impossibility. If the re-existence restriction obtains, then God cannot satisfy (a) and (b) at a time after I die any more than God can bring about a married bachelor or a four-sided triangle. It might remain within God's power to satisfy condition (a) by itself. God might certainly be able to bring it about that some materials get structured humanwise in a way that exactly resembles me at a certain time in my life. But what God cannot do if the re-existence restriction obtains is to bring it about that those materials compose me and not merely a replica of me. God cannot satisfy condition (b) at a time after I die, and so God cannot satisfy the conjunction of (a) and (b) at a time after I die.

To defend the compatibility thesis hylomorphists need a response to this argument. The response that I want to consider targets Premise 2. Defenders of the compatibility thesis can look both to undermine the argument for Premise 2 and to argue directly against it. When it comes to the first task, there are at least two strategies they can follow. One strategy argues that the re-existence restriction fails to obtain in the case of resurrection since there are parts of us that continue to exist after we 
die. Call this the 'surviving part strategy'. According to one version of it, each of us possesses an immaterial part, a rational soul, which persists after we die. At the resurrection, God reattaches my rational soul to a body, and this ensures that I am the one who is raised and not someone else. Something like this, I take it, is Aquinas' strategy. ${ }^{14}$ Unfortunately, this version of the strategy does not appear compatible with the kind of hylomorphism I've described. That kind of hylomorphism claims that we are exhaustively decomposable into fundamental physical materials, something that appears incompatible with the existence of an immaterial part.

Hylomorphists who endorse the surviving part strategy could say one of two things here. First, they could argue that the exhaustive decomposition I described earlier is actually compatible with immaterial parts in the sense postulated by philosophers like Aquinas since there is an equivocation on the term 'part'. Understood in one sense, there are no parts other than those that either are fundamental physical particles or that are exhaustively decomposable into them. But an immaterial soul is not a part in this sense. Koslicki (2008), for instance, distinguishes between formal and material parts. The fundamental physical particles that compose me are material parts, whereas an immaterial soul, as Aquinas understands it, is a formal part. ${ }^{15}$ Following this line of reasoning, hylomorphists could argue that the earlier claim that organisms are exhaustively decomposable into fundamental physical particles remains compatible with the existence of immaterial souls, for the earlier claim concerns material parts, whereas the latter concerns formal ones.

Alternatively, hylomorphists who endorse the surviving part strategy could argue that there are material parts of us that persist after we die. Each of us is endowed with a unique physical component, they could say, one that plays the same theoretical role as an immaterial soul, but that does not pose even a prima facie challenge to the claim that we are exhaustively decomposable into physical particles.

A second strategy for undermining the argument for Premise 2 argues against the re-existence restriction directly. Call this the 'gappy existence strategy'. Hershenov (2003), for instance, argues that there are counterexamples to the re-existence restriction. Certain artefacts (some artworks, as well as guns, and watches) can remain numerically the same

${ }^{14}$ See for instance Summa Theologiae Ia, 84-89, and IIIa Supplement, Questions 75-80.

${ }^{15}$ Leftow (2001) provides a useful discussion of what this amounts to for Aquinas. 
despite being disassembled and later reassembled. An accused murderer on trial could not argue persuasively that the gun reassembled by police in the courtroom could not be the alleged murder weapon on the grounds that the murder weapon ceased to exist when police disassembled it at the crime scene. The reason we don't accept the accused murderer's argument is that intuitively we tend to think that numerically one and the same gun can be disassembled and later reassembled. Hershenov goes on to argue that people are similar to artefacts like the gun, and so it is plausible to suppose that we too could undergo disassembly at death and later reassembly at the resurrection.

Critics of Hershenov's response might object that his examples are beside the point. Resurrection concerns not artefacts but living things, and living things like us are not analogous to the artefacts Hershenov considers. In particular, living things unlike artefacts persist on account of their lives, on account of the continuous biological activities in which their components are caught up. An argument along these lines is suggested by van Inwagen:

The atoms of which I am composed occupy at each instant the positions they do because of the operations of certain processes within me (those processes that taken collectively, constitute my being alive) ... [I]f a man ... is totally destroyed (as in the case of cremation) then he can never be reconstituted, for the causal chain has been irrevocably broken. Thus if God collects the atoms that used to constitute the man and 'reassembles' them, they will occupy the positions relative to one another because of God's miracle and not because of the operation of the natural processes that, taken collectively, were the life of the man (1978: 119).

Van Inwagen's reasoning suggests that if God were to reassemble physical particles in a way that exactly resembled me at some time prior to my death, the reassembled individual would not be me since it would not be living my same life; it would not be continuing the same biological activity in which the physical particles that compose me now are currently engaged. Once that activity ceases - at least in the radical way that results from something like cremation - it cannot recommence. ${ }^{16}$ But if my life cannot recommence, then I cannot exist again at a time

${ }^{16}$ In his later work van Inwagen states the idea as follows: 'If a life has been disrupted, it can never begin again; any life that is going on after its disruption is not that life' (1990: 147). 
after I die, and so I cannot be the individual who is composed of any materials God assembles after my death.

Hershenov tries to meet this type of objection by challenging the necessity of biological continuity for animal existence. Imagine, he says, a human zygote that comes into existence at time $t_{1}$ in world $w_{1}$ and persists through time $t_{2}$. In another possible world, $w_{2}$, that same zygote is destroyed an instant after it comes into existence. Its parts are then reassembled at time $t_{2}$ in a way that is indistinguishable from the way they are assembled at $t_{2}$ in $w_{1}$. The intuition we are supposed to have is that there is no relevant difference between the zygote that exists at $t_{2}$ in $\mathrm{w}_{1}$ and the zygote that exists at $\mathrm{t}_{2}$ in $\mathrm{w}_{2}$. If that is the case, then biological continuity is irrelevant to the persistence of human organisms, for in both $\mathrm{w}_{1}$ and $\mathrm{w}_{2}$ numerically one and the same zygote persists through $\mathrm{t}_{2}$, yet in $\mathrm{w}_{2}$ there is no biological continuity since the zygote in $\mathrm{w}_{2}$ underwent instantaneous destruction. What is true of the zygote, Hershenov continues, is also true of each of us: biological continuity is not necessary for our persistence. Consequently, even if I am utterly destroyed when I die, it is still metaphysically possible for God to reassemble my parts so that the resulting individual is I myself and not a mere replica.

The problem critics are likely to have with this argument is that it appears covertly question-begging: someone is not likely to have Hershenov's intuition about organisms, zygotic or otherwise, unless he or she already accepts Hershenov's conclusion; that is, unless he or she already believes that biological continuity is not necessary for one and the same organism to persist. Someone like van Inwagen who thinks to the contrary that biological continuity is necessary for organic persistence will think that Hershenov's intuition is exactly wrong: in $\mathrm{w}_{2}$ it is not numerically the same zygote that exists at both $t_{1}$ and $t_{2}$. For this reason defenders of the compatibility thesis might try a response different from Hershenov's.

An alternative way of responding to van Inwagen's argument for the re-existence restriction does not look to challenge the necessity of biological continuity for organic persistence, nor does it depend on analogies between artefacts and living things. It instead focuses on events, and on the possibility that one and the same event can cease and then recommence at a later time.

A sporting event might be suspended on account of the weather. The activities of the coaches, players, and spectators that constitute the event all cease to occur, and in that sense the event itself ceases to exist. The 
same event can nevertheless recommence at a later time provided the right conditions are satisfied (conditions usually stated in the league's bylaws). How is the example of events supposed to help with resurrection? Hylomorphists can argue that my life is an event whose occurrence is sufficient for me to exist. If lives are events like the aforementioned sporting events, if they are capable of ceasing and later recommencing, then there is a basis for rejecting the re-existence restriction for living things such as human beings. If my life ceases to exist when I die, it can still recommence at a later time, and if my life recommences, I will once again exist. Here is a rough sketch of how hylomorphists might argue for this kind of view.

One popular account of events claims that events are property exemplifications (Goldman 1970, Kim 1973, Bennett 1988). An event, on this account, exists exactly if an object has a property at a time, or a number of objects stand in a relation at a time. With this understanding of events in mind consider again van Inwagen's notion of being caught up in a life (Section 1 above). A life in van Inwagen's sense seems to be a complex multigrade relation among a number of fundamental physical particles. For those particles to be caught up in something's life at a time thus appears to be an event in the aforementioned sense. Hylomorphists might now argue that when objects of these sorts stand in that type of relation (a dynamic structure) at a time, they compose a distinctive individual, a new substance, a living thing such as I am. When I die the event that is my life ceases to exist; the physical materials that compose me cease to stand in the relevant complex relation. It is nevertheless possible for an event that has ceased, to recommence again at a later time. Consequently, it is possible that the event that is my life might resume again at a time after I die. But if it is my life that recommences at a later time, it seems plausible to suppose that it is I myself who am living it, that I myself exist again when my life recommences. Consequently, if God can bring it about that my life recommences at a time after I die, that some physical materials take on the relevant dynamic structure, then God can bring it about that I exist at a time after I die.

Critics might still wonder: How is God able to guarantee that it is my life and not some other that recommences after I die? How, in other words, is God able to satisfy condition (b) on this account? One idea is that each person's life has a characteristic or set of characteristics that is entirely unique to it - a unique relation to God or perhaps a role in the universe that only my life can play, something like a vocation in Adams 
(1987) sense. ${ }^{17}$ Suppose that this is the case, and that $\mathrm{R}$ is a characteristic of this sort. Suppose now that I die, and at a later time God wills that my life should recommence, that physical materials should carry on the activities of a distinctively human life, and in particular the activities of a human life that has characteristic $\mathrm{R}$. Since $\mathrm{R}$ is unique to my life, since mine is the only life that can have R, it must be my life that recommences. And if it is my life that recommences, then it seems plausible to suppose that it is I myself and no one else who lives it. God is thus able to satisfy condition (b), to guarantee that I am the individual who is brought back from the dead.

I've just described two broad strategies hylomorphists can follow in response to the re-existence restriction. The surviving part strategy claims that the restriction is out of play when it comes to resurrection, and the gappy existence strategy claims that the restriction is false. According to both, the argument for Premise 2 founders. Defenders of the compatibility thesis can argue in addition that there is good prima facie reason to reject Premise 2. God has managed to bring it about once already that some materials have a distinctively human structure and compose me and not someone else. Since it has been within God's power to do this at times before my death, there is good reason to think it remains within God's power to do this at times after my death. If the reexistence restriction obtained, of course, then this would not be the case; there would be a difference in what God could do before and after my death. But, as we've seen, hylomorphists can follow at least two strategies for rejecting the restriction. So on balance, hylomorphists can say, we have good reason to think that God is capable of satisfying conditions (a) and (b); God can bring it about at a time after I die that some materials have a distinctively human structure and compose me and not someone else, and if that is the case, we have good reason to think that the compatibility thesis is true, that hylomorphism is compatible with the doctrine of resurrection.

I want to close by considering three objections van Inwagen raises to something he calls 'an "Aristotelian" account of resurrection' (1978: 119-120). I want to make it clear that the account he has in mind is not the hylomorphic account I've just described.

Van Inwagen's first objection is that it is possible for the physical particles that compose me to be destroyed. If that is the case, however,

${ }_{17}$ Perhaps this is one way of interpreting the doctrine that God specially creates each human soul. 
then it might be impossible for God to reassemble those very particles at a time after I die, and in that case, he concludes, resurrection would be impossible. Van Inwagen's second objection is that it is possible for the physical particles that compose me at a time to compose someone else at a different time. But if that is the case, it is difficult to see what principled basis there could be for determining who gets those particles at the resurrection. Van Inwagen's third objection concerns the kind of body I will have when I am resurrected. God could reassemble the physical particles that composed me when I was a young child into an exact replica of my childhood self. God could also, and perhaps even simultaneously, reassemble the physical particles that composed me when I was an old man into an exact replica of my elderly self. Both, it seems, could lay claim to being me, yet it is impossible that I should be identical to both.

Van Inwagen's arguments all implicitly assume that resurrection requires that the very same physical particles or materials that composed me at some time prior to my death should compose me when I am resurrected. But the hylomorphic account of resurrection I've described is not committed to this. The two strategies I've discussed are both compatible with God using physical materials other than those that composed me at any time prior to my death. ${ }^{18}$ What is crucial to resurrection on both accounts is not the sameness of physical materials but of something else: a surviving part or a life. On either account God can resurrect me using physical particles different from any that composed me prior to my death. It is thus irrelevant that some of those physical particles should have ceased to exist in the interim, as per van Inwagen's first objection. It is also irrelevant that some of those physical particles should have been shared with other people, as per van Inwagen's second objection. All that is relevant is that God bring it about that some physical materials or other be structured humanwise at a time after my death and either be connected to my surviving part or else continue the event that was my life.

An analogous point holds for van Inwagen's third objection. Suppose that God constructs a replica of my young self and a replica of my elderly self. Hylomorphism does not imply that I must be identical to either of

${ }^{18}$ It is thus compatible with St. Paul's idea (1 Cor 15: 35-44) that my resurrected body might be in some way different from the natural body I was initially born with, lived with, and died with. Paul calls it a 'spiritual body' (soma pneumatikon). 
these individuals. According to the surviving part strategy, I am identical to one of these individuals or the other only if God has willed that its body be joined to my surviving part. And according to the gappy existence strategy, I am identical to one of these individuals or the other only if God has willed that it be living my life. Since my life and my surviving part are unique to me on these accounts, they are not things that could be shared by multiple individuals, not even if those individuals are exact replicas of me at various stages of my life.

There is a great deal more that could be said about hylomorphism and the resurrection. I nevertheless hope that I've said enough here to build a preliminary case for their compatibility. ${ }^{19}$

\section{BIBLIOGRAPHY}

Adams, Robert Merrihew. 1987. 'Vocation', Faith and Philosophy, 4: 448-462 Bechtel, William. 2007. 'Reducing Psychology while Maintaining its Autonomy via Mechanistic Explanations', in The Matter of the Mind, Maurice Schouten and Looren de Jong, Huib, eds. (New York: Blackwell Publishing), pp. 172-198

Bennett, Jonathan. 1988. Events and Their Names (Indianapolis: Hackett Publishing)

Bickle, John. 2003. Philosophy and Neuroscience: A Ruthlessly Reductive Account (Dordrecht: Kluwer Academic Publishers)

Broad, C.D. 1925. The Mind and Its Place in Nature (London: Routledge \& Kegan Paul)

Campbell, Neil A. 1996. Biology, 4th Edition (Menlo Park, CA: The Benjamin/ Cummings Publishing Company, Inc.)

Campbell, Neil A., Jane B. Reece, and Lawrence G. Mitchell. 1999. Biology, 5th Edition (Menlo Park, CA: The Benjamin/Cummings Publishing Company). Craver, Carl F. 2007. Explaining the Brain: Mechanisms and the Mosaic Unity of Neuroscience (New York: Oxford UP)

Cummins, Robert. 1975. 'Functional Analysis', Journal of Philosophy, 72: 741-64

Dennett, Daniel C. 1978. 'Toward a Cognitive Theory of Consciousness', in Brainstorms (Cambridge, MA: Bradford Books)

Dennett, Daniel C. 1991. 'Real Patterns', Journal of Philosophy, 88: 27-51

Dewey, John. 1958. Experience and Nature (New York: Dover Publications)

Ellis, Brian. 2002. The Philosophy of Nature: A Guide to the New Essentialism (Montreal: McGill-Queen's University Press)

Fine, Kit. 1999. 'Things and Their Parts', Midwest Studies in Philosophy, 23: 61-74

${ }^{19}$ Acknowledgment: This paper was originally presented in Munich, at a conference for the Analytic Theology Project, generously funded by the John Templeton Foundation. 
Fodor, Jerry. 1968. 'The Appeal to Tacit Knowledge in Psychological Explanation', Journal of Philosophy, 65: 627-40

Furth, Montgomery. 1978. 'Transtemporal Stability in Aristotelian Substances', Journal of Philosophy, 75: 624-46

Garber, Daniel. 1985. 'Leibniz and the Foundations of Physics: The Middle Years', in The Natural Philosophy of Leibniz, Kathleen Okruhlik and James Robert Brown, eds. (Dordrecht: Reidel), pp. 27-130

Goldman, Alvin. 1970. A Theory of Human Action (Englewood Cliffs, NJ: Prentice-Hall)

Haldane, J.B.S. 1947. What Is Life? (New York: Boni and Gaer)

Hershenov, David. B. 2003. 'The Metaphysical Problem of Intermittent Existence and the Possibility of Resurrection', Faith and Philosophy, 20:24-36

Jaworski, William. 2011. Philosophy of Mind: A Comprehensive Introduction (Wiley-Blackwell)

Jaworski, William. 2012. 'Powers, Structures, and Minds', in Powers and Capacities in Philosophy: The New Aristotelianism, John Greco and Ruth Groff, eds. (New York: Routledge), pp. 145-171

Johnston, Mark. 2006. 'Hylomorphism', Journal of Philosophy, 103: 652-98

Kim, Jaegwon. 1976. 'Events as Property Exemplifications', in Action Theory, Myles Brand and Douglas Walton, eds. (Dordrecht, Holland: D. Reidel Publishing Co.), pp. 159-77. Reprinted in Kim 1993: 33-52.

Kim, Jaegwon. 1993. Supervenience and Mind (Cambridge: Cambridge UP)

Koslicki, Kathrin. 2008. The Structure of Objects (Oxford: Oxford UP)

Ladyman, James, and Don Ross. 2007. Every Thing Must Go: Metaphysics Naturalized (Oxford: Oxford UP)

Leftow, Brian. 2001. 'Souls Dipped in Dust', in Soul, Body, and Survival: Essays on the Metaphysics of Human Persons, Kevin Corcoran, ed. (Ithaca: Cornell University Press), pp. 120-138

Locke, John. 1959. An Essay Concerning Human Understanding, 2 vols. (New York, NY: Dover Publications, Inc.)

Lycan, William G. 1987. Consciousness (Cambridge, MA: MIT Press)

Mayr, Ernst. 1982. The Growth of Biological Thought: Diversity, Evolution, and Inheritance (Cambridge, MA: The Belknap Press of Harvard University)

Merleau-Ponty, Maurice. 2002. Phenomenology of Perception, 2nd Edition (London: Routledge)

Miller, Jonathan. 1982. The Body in Question (New York: Vintage Books)

Nussbaum, Martha and Hilary Putnam. 1992. 'Changing Aristotle's Mind', in Essays on Aristotle's De Anima, M. Nussbaum and A.O. Rorty, eds. (Oxford: Clarendon Press), pp. 27-56.

Oderberg, David. 2007. Real Essentialism (London: Routledge)

Putnam, Hilary. 1975. Mind, Language, and Reality: Philosophical Papers, Vol. 2. (New York: Cambridge UP) 
Ruse, Michael. 2001. Can a Darwinian Be a Christian? The Relationship between Science and Religion (Cambridge: Cambridge University Press)

Smith, Justin Erik Halldór. 2002. 'Leibniz's Hylomorphic Monad', History of Philosophy Quarterly, 19: 21-42

Sober, Elliott. 1985. 'Panglossian Functionalism and the Philosophy of Mind', Synthese, 64: 165-93

Sommerhoff, Gerd. 1969. 'The Abstract Characteristics of Living Systems', in Systems Thinking: Selected Readings, ed. by F.E. Emery (Harmondsworth: Penguin), pp. 147-202

Van Fraassen, Bas C. 1980. The Scientific Image (Oxford: Clarendon Press)

Van Inwagen, Peter. 1978. 'The Possibility of Resurrection', International Journal of Philosophy of Religion, 9: 114-121

Van Inwagen, Peter. 1990. Material Beings (Ithaca, NY: Cornell UP)

Young, J.Z. 1971. An Introduction to the Study of Man (Oxford: The Clarendon Press) 